\title{
The tunicate Salpa thompsoni ecology in the Southern Ocean. I. Distribution, biomass, demography and feeding ecophysiology
}

Received: 28 July 2004 / Accepted: 16 October 2005

(C) Springer-Verlag 2005

\begin{abstract}
Distribution, density, and feeding dynamics of the pelagic tunicate Salpa thompsoni have been investigated during the expedition ANTARKTIS XVIII/5b to the Eastern Bellingshausen Sea on board RV Polarstern in April 2001. This expedition was the German contribution to the field campaign of the Southern Ocean Global Ocean Ecosystems Dynamics Study (SO-GLOBEC). Salps were found at $31 \%$ of all RMT- 8 and Bongo stations. Their densities in the RMT-8 samples were low and did not exceed 4.8 ind $\mathrm{m}^{-2}$ and $7.4 \mathrm{mg} \mathrm{C} \mathrm{m}^{-2}$. However, maximum salp densities sampled with the Bongo net reached 56 ind $\mathrm{m}^{-2}$ and $341 \mathrm{mg} \mathrm{C} \mathrm{m}^{-2}$. A bimodal salp length frequency distribution was recorded over the shelf, and suggested two recent budding events. This was also confirmed by the developmental stage composition of solitary forms. Ingestion rates of aggregate forms increased from 2.8 to $13.9 \mu \mathrm{g}$ (pig) ind ${ }^{-1} \mathrm{day}^{-1}$ or from 0.25 to $2.38 \mathrm{mg} \mathrm{C}$ ind $^{-1}$ day $^{-1}$ in salps from 10 to $40 \mathrm{~mm}$ oral-atrial length, accounting for $25-75 \%$ of body carbon per day. Faecal pellet production rates were on average 0.08 pellet ind ${ }^{-1} \mathrm{~h}^{-1}$ with a pronounced diel pattern. Daily individual egestion rates in 13 and $30 \mathrm{~mm}$ aggregates ranged from 0.6 to $4.8 \mu \mathrm{g}$ (pig) day ${ }^{-1}$ or from 164 to $239 \mu \mathrm{g} \mathrm{C} \mathrm{day}^{-1}$. Assimilation efficiency ranged from 73 to $90 \%$ and from 65 to $76 \%$ in 13 and $30 \mathrm{~mm}$ aggregates, respectively. S. thompsoni exhibited similar ingestion and
\end{abstract}

Communicated by O. Kinne, Oldendorf/Luhe

E. A. Pakhomov ( $\square)$

Department of Earth and Ocean Sciences,

University of British Columbia, 6339 Stores Road,

V6T 1 Z4 Vancouver, BC, Canada

E-mail: epakhomov@eos.ubc.ca

C. D. Dubischar · V. Strass · M. Brichta $\cdot$ U. V. Bathmann

E. A. Pakhomov

Alfred Wegener Institute for Polar and Marine Research,

Am Handelshafen 12, 27515 Bremerhaven, Germany

E. A. Pakhomov

Department of Zoology, University of Fort Hare,

Private Bag X1314, 5700 Alice, South Africa egestion rates previously estimated for low Antarctic $\left(\sim 50^{\circ} \mathrm{S}\right)$ habitats. It has been suggested that the salp population was able to develop in the Eastern Bellingshausen Sea due to an intrusion into the area of the warm Upper Circumpolar Deep Water

\section{Introduction}

There has been an increasing interest in the pelagic tunicate Salpa thompsoni in the Southern Ocean during recent decades (e.g. Huntley et al. 1989; Nishikawa et al. 1995; Pakhomov et al. 2002; Atkinson et al. 2004). This is because $S$. thompsoni has been identified as the most important large filter-feeder of the Southern Ocean in terms of wet mass and ranking the third among metazoans, including copepods and Antarctic krill Euphausia superba, in terms of dry or carbon mass (Voronina 1998; Pakhomov et al. 2002). Salpa thompsoni is recognized as a microphage of key importance, as it is able to efficiently re-package small particles into large fast sinking faeces, thereby playing a major role in channelling biogenic carbon from surface waters into long-living pools and to the ocean's interior and seafloor (Le Fèvre et al. 1998; Moline et al. 2000; Walsh et al. 2001). Although salps probably play an insignificant role in the diets of penguins and mammals, they may be consumed by a number of the Southern Ocean top predators (see review in Pakhomov et al. 2002). Finally, salps have the ability to undergo an explosive development and likely outcompete other zooplankton species, including Antarctic krill, thus altering the high Antarctic pelagic food web economy (Loeb et al. 1997; Walsh et al. 2001).

Historically, $S$. thompsoni is regarded as an organism found in low Antarctic $\left(45-55^{\circ} \mathrm{S}\right)$ waters with only limited records in the coastal seas surrounding the Antarctic continent (Foxton 1966). However, it has recently been postulated that the salp distribution might have changed over the last half a century by shifting southward (Pakhomov et al. 2002; Atkinson et al. 2004). Since 
S. thompsoni is a cold-temperate species, the above indicates that a large-scale environmental shift in Antarctic regions may have occurred, or is in progress (de la Mare 1997; Levitus et al. 2000). It has been suggested that the southward expansion of $S$. thompsoni may be coupled with a dramatic fall in the stock and productivity of Antarctic krill due to a decrease in the spatial extent of its biotope (Pakhomov et al. 2002) or significant decrease in the sea ice cover (Atkinson et al. 2004). This in turn may affect the Antarctic marine food web and krill resource management (Loeb et al. 1997). The salp expansion to the areas previously considered as the Antarctic krill domain may, however, insert some biological feedbacks on salp populations, resulting in modifications to the salp life cycle (Casareto and Nemoto 1986; Chiba et al. 1999). In addition, salp populations may collapse at elevated particle concentrations (Harbison et al. 1986; Perissinotto and Pakhomov 1998a; Pakhomov et al. 2003), which are relatively normal at the marginal ice zone. As a consequence, studies on krill and salp interactions, and particularly salp ecology, are important challenges if we wish to understand how the Southern Ocean biological pump would react to global climate change.

Most of our knowledge of $S$. thompsoni large-scale distribution, biology and life cycle comes from the classical work by Foxton (1966) based on data collected during the Discovery expeditions in the first half of the last century. There are numerous literature sources on salp meso-scale distribution and density in recent decades, but only a handful of papers deal with biology or feeding ecophysiology of $S$. thompsoni (see review Pakhomov et al. 2002). Still, little is known on $S$. thompsoni general ecology and this information is particularly scarce in the region south of $60^{\circ} \mathrm{S}$ (Casareto and Nemoto 1986; Chiba et al. 1999; Nicol et al. 2000). During April and May 2001, a German Southern Ocean Global Ocean Ecosystems Dynamics (SO-GLOBEC) cruise was conducted to examine interactions between zooplankton and physical conditions in the Bellingshausen Sea during the austral autumn (Bathmann 2002). The main aims of this study, which will be presented in two sister papers, were: first (part one), to describe distribution, biology and feeding ecophysiology; and second (part two), to investigate biometry and proximate/elemental composition of $S$. thompsoni population at high latitudes of the Eastern Bellingshausen Sea.

\section{Materials and methods}

Samples and measurements were collected during the expedition ANTARKTIS XVIII/5b to the Eastern Bellingshausen Sea on board RV Polarstern conducted between April 18 and May 1, 2001 as the German contribution to the field campaign of the SO-GLOBEC (Fig. 1; Bathmann 2002). Vertical profiles of temperature, salinity and density were derived at each station from measurements made by lowering a Sea-Bird Electronics
SBE 911plus conductivity, temperature and depth (CTD) at hydrographic stations. The CTD and peripheral instruments were attached to a Sea-Bird SBE 32 Carousel multi-bottle water sampler holding 24 12-1 bottles. The performance of the water sampler was controlled by use of SIS reversing thermometers and pressure gauges attached to eight of the water bottles. Salinity derived from the CTD measurements was re-calibrated after the cruise by comparison to salinity samples, taken from the water bottles, which were analysed by use of a GuildlineAutosal-8400A salinometer to an accuracy generally better than $0.001 \mathrm{U}$ on the practical salinity scale. The final accuracy of the recalibrated CTD salinities is estimated as 0.004 . The temperature sensor was calibrated at the factory roughly half a year prior to the cruise to an accuracy better than $0.0001{ }^{\circ} \mathrm{C}$. Water samples for total chlorophyll- $a$ (Chl-a) and particulate organic carbon (POC) were collected at eight standard depths: 0, 10, 25, $50,75,100,150$ and $200 \mathrm{~m}$. Chl- $a$ was extracted from $1,000 \mathrm{ml}$ aliquots in $90 \%$ acetone for $12 \mathrm{~h}$ in the dark at $-18^{\circ} \mathrm{C}$. Concentrations were calculated from fluorescence readings on a Turner Design 10AU fluorometer before and after acidification with $\mathrm{HCl}$ (Strickland and Parsons 1968). To measure POC, 1,000 ml aliquots were filtered through pre-combusted $\mathrm{GF} / \mathrm{F}$ filters, frozen at $-80^{\circ} \mathrm{C}$ and measured in the laboratory with a Carlo Erba 1500 analyser.

Salp distribution, density and biology

Salps, S. thompsoni, were sampled with oblique within the top 200-300 m water column or surface tows using RMT-8 trawl (mouth area $8 \mathrm{~m}^{-2}, 4.5 \mathrm{~mm}$ mesh) and with vertical tows, generally $0-300 \mathrm{~m}$, using a Bongo net $\left(0.5 \mathrm{~m}^{-2}, 0.3 \mathrm{~mm}\right)$ fitted with a closed 31 cod-end. Besides samples conducted in the Eastern Bellingshausen Sea (Fig. 1), two midday Bongo samples were collected on May 3, 2001 near Jubany Base (Sta. 330, $\left.62^{\circ} 17.7^{\prime} \mathrm{S}-58^{\circ} 44.5^{\prime} \mathrm{W}\right)$, King George Island, South Shetland Islands (Bathmann 2002). On board, salps were immediately sorted randomly into three subsamples. One was deep frozen $\left(-80^{\circ} \mathrm{C}\right)$ for future biological, elemental and proximate composition as well as for additional gut pigment content analysis. The second subsample was used for on board gut pigment content extractions. The last subsample was fixed in $4 \%$ buffered formaldehyde for subsequent biological analysis. Live salps, obtained only at stations 328 and 330 (near $J u$ bany Base), were used for egestion experiments. Detailed descriptions of elemental and proximate analyses will be presented in Dubischar et al. (2005).

In the laboratory, the salps were counted, separated into aggregate and solitary forms and measured for total (from tip to tip) and body [oral-atrial (OA) distance] length to the nearest millimetre according to Foxton (1966). The maturity stages of $S$. thompsoni have been previously described in several papers (e.g. Foxton 1966; Casareto and Nemoto 1986; Chiba et al. 1999; Daponte 
Fig. 1 Location of stations conducted during the ANTARKTIS XVIII/5b cruise to the Eastern Bellingshausen Sea between 18 April and 1 May 2001 on board RV Polarstern

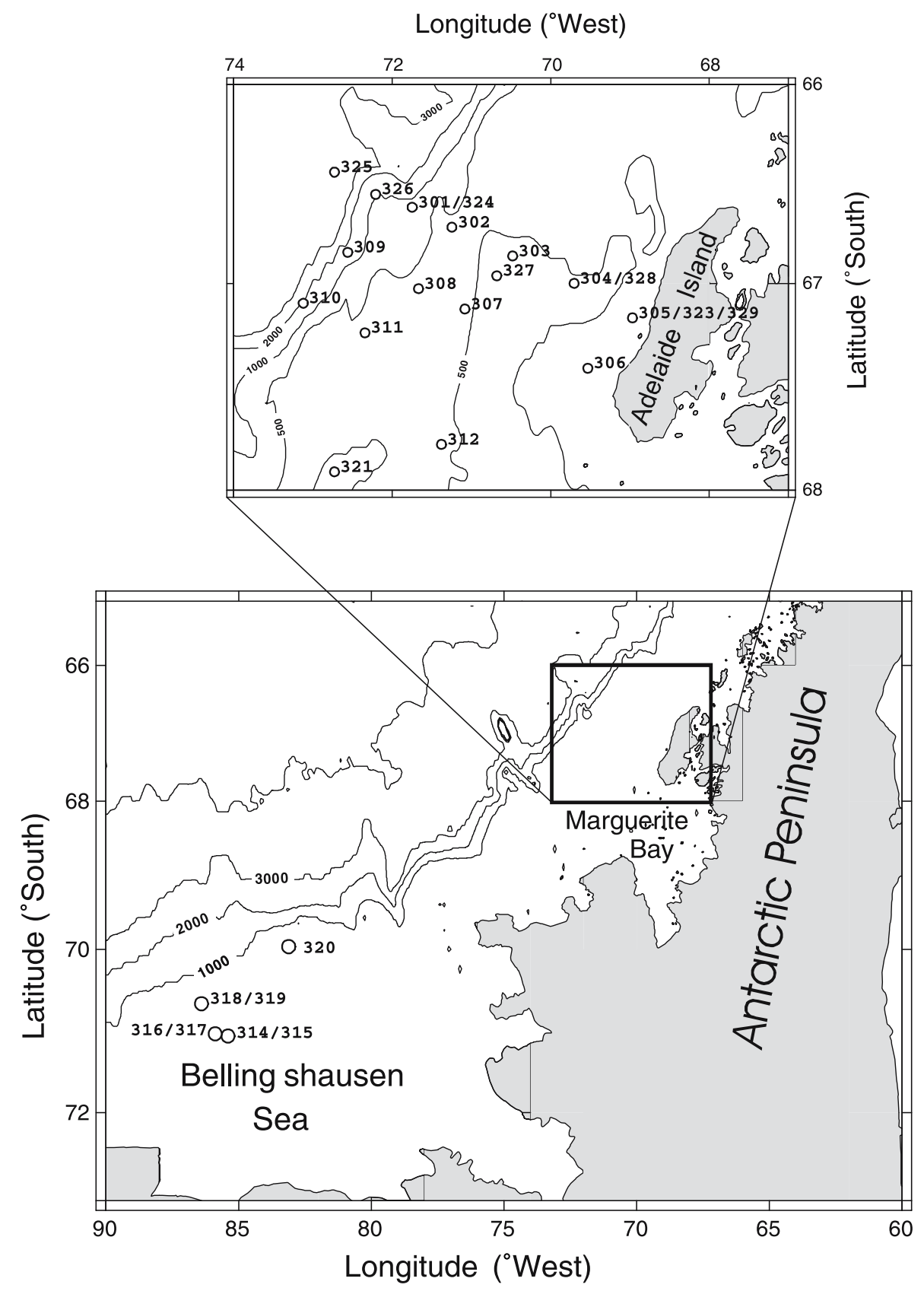

et al. 2001). The maturity stages of aggregates were determined according to morphological characteristics of the embryo inside an aggregate body. Five different stages (from 0 to 4 ) were classified according to gradual growth of the embryo. At stage 0 , the ovarian sac is spherical with no sign of embryo development. By stage 4 , the embryo, often $>4 \mathrm{~mm}$ in length, resembles in all features the early oozoid (see pictures in Foxton 1966; Daponte et al. 2001). Stage 'spent' was identified by the presence of a placentar scar, which indicated that the embryo has been released. Finally, we observed some embryos with abnormal development, for example, no embryos (failed fertilization), disrupted embryo development, and absorption of the embryo. Following Chiba et al. (1999), we classified such stages as ' $X$ '. The developmental stages of solitary forms were determined according to the morphology of the stolon as described in detail in Foxton (1966), Casareto and Nemoto (1986) and Daponte et al. (2001).

Salp gut pigment contents, ingestion and egestion rates

Salp ingestion rates were determined using the gut fluorescence technique (Mackas and Bohrer 1976). For the gut pigment analyses, salps either immediately after capture or after thawing were separated into aggregate and solitary forms, measured and placed in plastic tubes with $10-50 \mathrm{ml}$ (depending of the salp size, one salp per tube) of $90 \%$ acetone and stored at $-18^{\circ} \mathrm{C}$ for $\approx 24 \mathrm{~h}$. 
After centrifugation $(5,000 \mathrm{rpm}), \mathrm{Chl}-a$ and phaeopigments, were measured with a Turner Designs 10AU fluorometer, before and after acidification (Mackas and Bohrer 1976). Gut contents were expressed in terms of pigment equivalents per individual and calculated according to Strickland and Parsons (1968) as modified by Conover et al. (1986). When the Chl- $a$ /phaeopigment ratio of the gut content was higher than 0.25 , total pigment levels were corrected according to Baars and Helling (1985). As no gut evacuation rate $(k)$ was measured during this expedition, literature values were used. The $k$-values for salps were assumed to be $0.25 \mathrm{~h}^{-1}$ (Drits and Semenova 1989; Perissinotto and Pakhomov 1998b; Pakhomov and Froneman 2004). The gut pigment loss was assumed to be $\sim 10 \%$ after Perissinotto and Pakhomov (1998b) and Pakhomov and Froneman (2004). Previous observations did not show a diel pattern in gut pigment contents of $S$. thompsoni (Perissinotto and Pakhomov 1998b; Pakhomov and Froneman 2004). Therefore, daily ingestion rates (I, ng (pig) ind ${ }^{-1}$ day $^{-1}$ ) were estimated from the relation: $I=(k G 24) \cdot 1.1$, where $G$ is a mean gut pigment content (ng (pig) ind $^{-1}$ ) and $k$ is the gut evacuation rate constant $\left(\mathrm{h}^{-1}\right)$. To convert pigment concentration into organic carbon in the Eastern Bellingshausen Sea an average POC:Chl- $a+$ phaeopigments (=C:pigment) ratio of $91 \pm 69$ (range $23-218, n=7$ ), obtained at $10 \mathrm{~m}$ depth at stations where salps were collected, was employed (M. Brichta and A. Belem, unpublished). To reconstruct a full energy budget for $S$. thompsoni, $\mathrm{C}$ :pigment ratios at stations where egestion rate experiments were conducted were used. At stations 328 and 330, C:pigment ratios were 64.5 and 105, respectively.

To estimate faecal pellet production rates, immediately after the tow 3-5 intact, actively swimming salps were placed into 10-20 1 containers filled with surface seawater. Containers with experimental animals were kept in darkness at the ambient seawater temperature $\left(\sim 0^{\circ} \mathrm{C}\right.$ ). Incubations lasted for $12 \mathrm{~h}$ (to cover $6 \mathrm{~h}$ of daylight and $6 \mathrm{~h}$ of darkness) and water was gently replaced every $4 \mathrm{~h}$. After the experiments, salps were frozen at $-80^{\circ} \mathrm{C}$ for subsequent elemental and proximate analyses. Every hour during the course of the experiment, faecal pellets were counted and gently collected with a glass pipette into $0.2 \mu \mathrm{m}$-filtered seawater. The sinking velocities, pigment and $\mathrm{C} / \mathrm{N}$ content of faecal pellets were then measured. The measurements of sinking rates were conducted in a plastic bottle $(8 \mathrm{~cm}$ in diameter and $40 \mathrm{~cm}$ in length) filled with a $0.2 \mu \mathrm{m}$-filtered surface seawater at $0^{\circ} \mathrm{C}$. To measure sinking velocities, faecal pellets were introduced just under the surface and the transit time from 5 to 15 and 15 to $30 \mathrm{~cm}$ were measured and then averaged. Faecal pellets were then individually placed into $200 \mathrm{ml}$ particle-free seawater and taken apart using an ultra-sound system. After proper mixing, $100 \mathrm{ml}$ of the mixture was filtered onto $\mathrm{GF} / \mathrm{F}$ filter for pigment content analysis as described above. Another $100 \mathrm{ml}$ were filtered on the
Fig. 2 Vertical distributions of potential temperature (a) and salinity (b) along a horizontal section that runs over $225 \mathrm{~km}$ in a southeasterly direction from $66^{\circ} 20^{\prime} \mathrm{S}, 73^{\circ} 00^{\prime} \mathrm{W}$ in the deep ocean across the continental shelf towards Adelaide Island. CTD station positions and numbers are indicated on the top $X$-axis
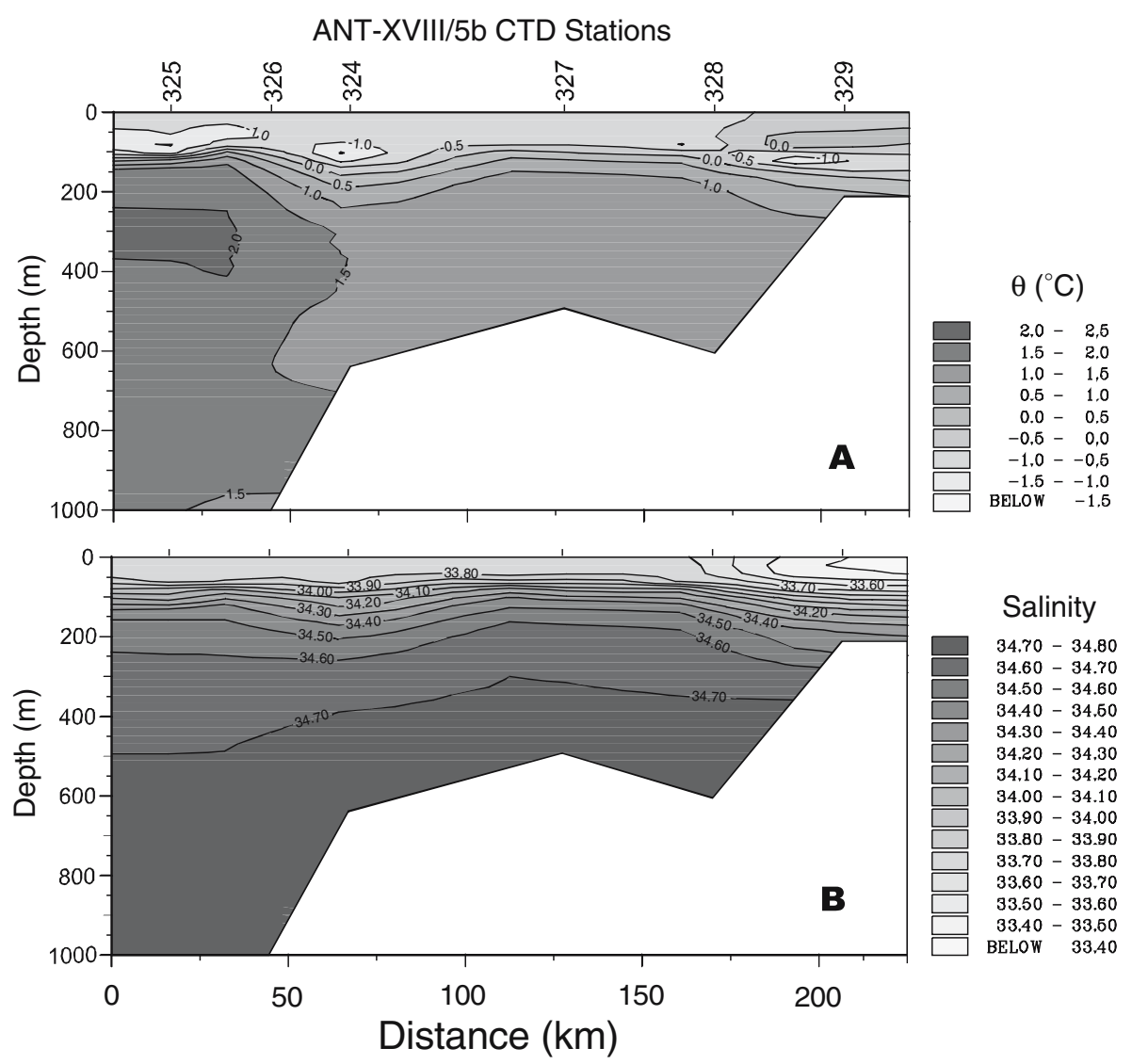
pre-combusted $\mathrm{GF} / \mathrm{F}$ filters and immediately frozen at $-80^{\circ} \mathrm{C}$ for subsequent $\mathrm{C} / \mathrm{N}$ analysis. In addition to surface Chl- $a$ measurements at stations where egestion rates were determined (Sta. 328 and 330), 1,000 $\mathrm{ml}$ aliquots were filtered through pre-combusted GFF filters and frozen at $-80^{\circ} \mathrm{C}$ for further $\mathrm{C} / \mathrm{N}$ analysis. The carbon and nitrogen content was determined with a Carlo Erba 1500 analyser.

\section{Results}

\section{Environmental parameters}

\section{Water mass characteristics}

Underway measurements of currents in the depth range $100-150 \mathrm{~m}$ with the vessel-mounted Acoustic Doppler Current Profiler (ADCP) revealed a current core with a general north-northeast direction along the shelf break and a reversed, sluggish flow with velocities $<0.05 \mathrm{~cm} \mathrm{~s}^{-1}$ along the coastline off Adelaide Island (Cisewski et al. 2002; Klinck et al. 2004). The water masses on the continental shelf of the Eastern Bellingshausen Sea were to a large extent of oceanic origin (Fig. 2). The major oceanic source water mass is the Upper Circumpolar Deep Water (UCDW). The UCDW occupied the depth range between 200 and $400 \mathrm{~m}$ in the deep open ocean (Sta. 325 in Fig. 2a, b) and had core potential temperatures $\theta>2^{\circ} \mathrm{C}$ and salinities between 34.55 and 34.68. Because the UCDW core was situated above the sill depth of the shelf break, $\sim 600 \mathrm{~m}$, in the Eastern Bellingshausen Sea, and because the isopycnal slope (not shown) was minor, warmer UCDW rather easily penetrated onto the shelf (Klinck et al. 2004). There, it was modified by mixing with Antarctic Surface Water (ASW; $-0.5^{\circ} \mathrm{C}<\theta<0.5^{\circ} \mathrm{C}, S<33.8$ ) from the mixed layer above $50 \mathrm{~m}$ and with Winter Water (WW; $\left.\theta<-1{ }^{\circ} \mathrm{C}, 33.8<S<34.2\right)$ occurring in the seasonal pycnocline in the depth range $50-150 \mathrm{~m}$ (Fig. 2). Even modified UCDW had temperatures exceeding $1^{\circ} \mathrm{C}$. It occupied the entire depth range below the permanent pycnocline, $\sim 100-150 \mathrm{~m}$. Only where the continental shelf was shallower than $200 \mathrm{~m}$ in the vicinity of the coast (Sta. 329 in Fig. 2) the ASW and WW did occupy the entire water column. The observation of a dominant influence of oceanic water masses over the shelf in the Eastern Bellingshausen Sea corroborates earlier observations made by Smith et al. (1999).
Fig. 3 Vertical distribution of chlorophyll- $a\left(\mathrm{mg} \mathrm{m}^{-3}\right)$ along a horizontal section across the continental shelf towards Adelaide Island during 18-19 April 2001 (a) and 28 April-1 May 2001 (b)
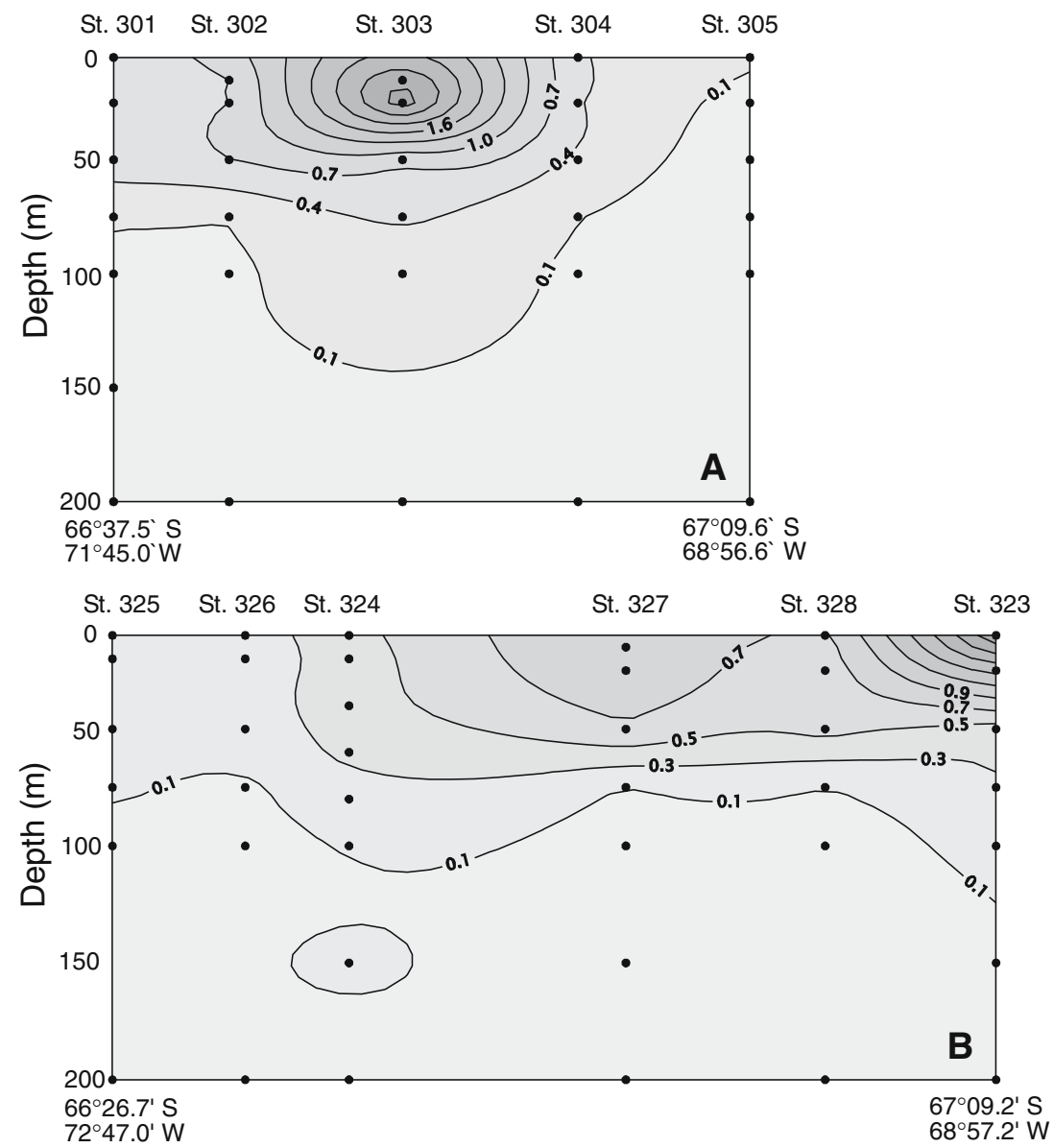


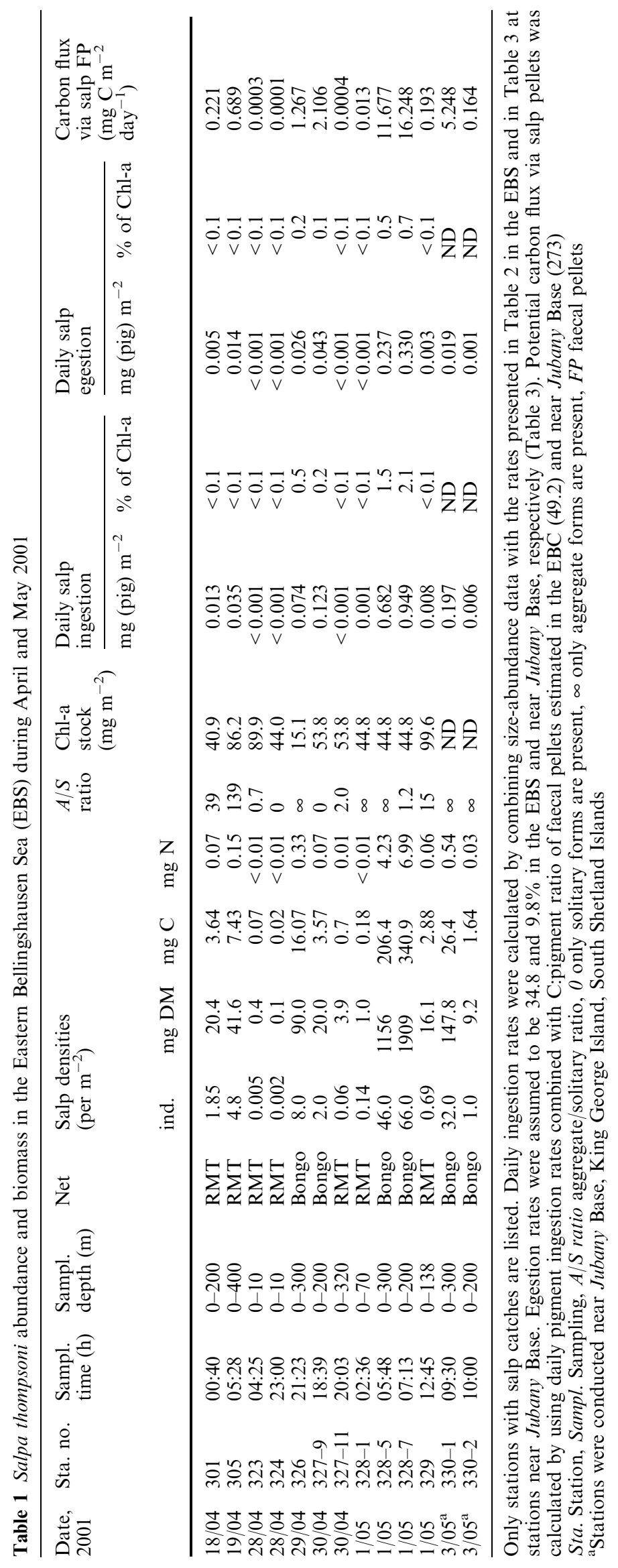




\section{Chlorophyll-a concentrations}

In open water stations, Chl- $a$ concentrations sharply decreased below $50 \mathrm{~m}$ depth and ranged from 0.2 to $2.4 \mathrm{mg} \mathrm{m}^{-3}$ in the upper layers (Fig. 3). Depth integrated Chl- $a$ stocks $(0-200 \mathrm{~m})$ varied between 15 and $165 \mathrm{mg} \mathrm{m}^{-2}$. At the beginning of the survey (Stns. 301$305)$, the highest Chl- $a$ concentrations $\left(>1 \mathrm{mg} \mathrm{m}^{-3}\right.$ and $>50 \mathrm{mg} \mathrm{m}^{-2}$ ) were observed at the middle shelf station 303 (Fig. 3a). Twelve days later (Stns. 323-328), Chl-a concentrations were lower and elevated concentrations $\left(>0.7 \mathrm{mg} \mathrm{m}^{-3}\right)$ were observed at the inner shelf stations 323 and 327 (Fig. 3b). At the ice stations (Stns. 314$318)$, Chl- $a$ concentrations were low and never exceeded $0.3 \mathrm{mg} \mathrm{m}^{-3}$ and $25 \mathrm{mg} \mathrm{m}^{-2}$ (Brichta and Belem 2002).

Salp distribution, density and biology

In the Eastern Bellingshausen Sea, S. thompsoni were found at $41 \%$ of all RMT-8 stations (7 of 17) and at $19 \%$ of all Bongo net stations (3 of 16). Salp densities estimated using the RMT- 8 trawl at stations where salps were collected ranged from 0.1 to 4.8 ind $\mathrm{m}^{-2}$, from 1 to $42 \mathrm{mg} \mathrm{DW} \mathrm{m} \mathrm{m}^{-2}$ and from 0.2 to $7.4 \mathrm{mg} \mathrm{C} \mathrm{m}^{-2}$ (Table 1). The mean densities, including all RMT-8 (including hauls with no salps) hauls, were $0.5 \pm 1.3$ ind $\mathrm{m}^{-2}, 5.5 \pm 11.8 \mathrm{mg} \mathrm{DW} \mathrm{m}^{-2}$ and $1.0 \pm 2.1 \mathrm{mg} \mathrm{C} \mathrm{m}^{-2}$. Salp densities in Bongo net samples ranged from 2 to 56 ind $\mathrm{m}^{-2}$, from 20 to $1,909 \mathrm{mg} \mathrm{DW} \mathrm{m} \mathrm{m}^{-2}$ and from 3.6 to $341 \mathrm{mg} \mathrm{C} \mathrm{m}^{-2}$ (Table 1). The mean densities, including all Bongo hauls, were $3.9 \pm 13.6$ ind $\mathrm{m}^{-2}$, $97 \pm 371 \mathrm{mg} \mathrm{DW} \mathrm{m}^{-2}$ and $17.3 \pm 66.2 \mathrm{mg} \mathrm{C} \mathrm{m}^{-2}$. Average densities obtained using RMT-8 trawls were $\sim 8$ (abundance) to $\sim 17$ (biomass) fold lower than densities obtained using Bongo nets. The highest salp concentrations (Bongo net samples) were recorded at station 328 , situated in the inner part of the shelf region, while elevated densities (RMT-8 trawl stations) were also obtained over the shelf break and continental slope (Fig. 1, Table 1). Near Jubany Base (Sta. 330), densities of $S$. thompsoni (OA length $10-15 \mathrm{~mm}$ ) ranged from 1 to 32 ind $\mathrm{m}^{-2}$, from 9 to $148 \mathrm{mg} \mathrm{DW} \mathrm{m}^{-2}$ and from 1.6 to $26.4 \mathrm{mg} \mathrm{C} \mathrm{m}^{-2}$ (Table 1). Salp densities were not related to Chl- $a$ concentrations or to $0-200 \mathrm{~m}$ averaged seawater temperatures (Pearson's correlations, in both cases $P>0.1$ ), possibly due to the limited number of observations (only eight stations with salps) and the inconsistency in the sampling depth (Table 1).

In the Eastern Bellingshausen Sea, OA length of aggregate forms of $S$. thompsoni varied between 6 and $42 \mathrm{~mm}$ with two distinct modes at $10-15$ and $28-31 \mathrm{~mm}$ (Fig. 4). Early developmental stages (0-2) predominated, accounting for $74 \%$ of all salps analysed. The contribution of stages 3 and 4 was negligible $(3.5 \%)$, while spent salps and salps with disrupted/no embryos accounted for 10 and $13 \%$, respectively (Fig. 4). The OA length of solitary forms ranged from 21 to $111 \mathrm{~mm}$, with a single peak at $29-32 \mathrm{~mm}$ (Fig. 4). The $29-32 \mathrm{~mm}$ oozoids (Sta. 328) were at stage 2 but retained all features of embryos, e.g. the large eleoblast and placenta were present (Fig. 5). Also, the nucleus (oesophagus) was smaller than eleoblast and was white in colour. In addition, a single oozoid at stage 3 with OA length of $43 \mathrm{~mm}$ was found with reduced eleoblast and placenta (Fig. 5). This specimen was feeding, as its nucleus was olive-green in colour. Overall, the immature stage 2 dominated $(32 \%)$ among solitary forms. The contribution of stages ready for the chain release (Figs. 4b, 5b) was very low, accounting for $0-3 \%$. Despite approximately $10 \%$ of all aggregates being spent, no embryos (stage 0) have been sampled in the region of investigation (Fig. 4). Although there were stations with only aggregate or solitary forms, the aggregate/solitary ratio, where both were present, varied between 0.7 and 139 (Table 1).

Size distribution and developmental composition of aggregate forms at representative stations are presented on Fig. 6. Two size groups were again observed at all stations. There was a substantial shift in both size distribution and developmental composition between the beginning (18-19 April) and the end (1 May) of the survey, indicating possible salp growth and development (Fig. 6). For example, there was a clear shift from domination of stage $0(48-51 \%)$ to stage $2(34-47 \%)$ at the beginning and at the end of the observed period (Fig. 6). The contribution of aggregates with disrupted/ no embryos was higher ( $\sim 16$ vs. $\sim 8 \%)$ at the beginning of the survey. This was due to the higher contribution of stage $\mathrm{X}(\sim 20 \%$ among salps with OA length $<15 \mathrm{~mm}$ vs. $\sim 8 \%$ among salps $>15 \mathrm{~mm}$ ) in smaller size groups, which predominated at the beginning of the survey (Fig. 6).

\section{Salp feeding ecophysiology}

Gut pigment contents of both aggregate and solitary forms were positively correlated with body size (Fig. 7). Ingestion rates of aggregate forms increased from 2.8 to $13.9 \mu \mathrm{g}$ (pig) ind ${ }^{-1} \mathrm{day}^{-1}$ or 0.25 to $2.38 \mathrm{mg} \mathrm{C}$ ind $^{-1}$ day $^{-1}$ in salps from 10 to $40 \mathrm{~mm} \mathrm{OA}$ length (Table 2). Daily ration, however, decreased from 75 to $25 \%$ of body carbon within the same size range (Table 2). Similarly, ingestion rates of solitary forms increased from 0.15 to $96 \mu \mathrm{g}$ (pig) ind ${ }^{-1}$ day $^{-1}$ or 0.01 to $8.74 \mathrm{mg} \mathrm{C}$ ind $^{-1}$ day $^{-1}$ in oozoids from 20 to $80 \mathrm{~mm}$ OA length (Table 2). Similarly, the daily ration increased from 0.5 to $36 \%$ of body carbon in 20 to $80 \mathrm{~mm}$ oozoids (Table 2 ).

Faecal pellet production rates were similar in both experiments, averaging 0.08 pellet ind ${ }^{-1} \mathrm{~h}^{-1}$, and were substantially lower during daylight hours than during darkness ( 0.04 vs. 0.13 pellet ind $\left.{ }^{-1} \mathrm{~h}^{-1}\right)$. Egestion rates displayed similar diel pattern with average values of 6.8 and $9.9 \mu \mathrm{g} \mathrm{C}$ ind $^{-1} \mathrm{~h}^{-1}$ in 13 and $30 \mathrm{~mm}$ aggregates, respectively (Fig. 8). Daily individual egestion rates in 13 and $30 \mathrm{~mm}$ aggregates ranged from 0.6 to 

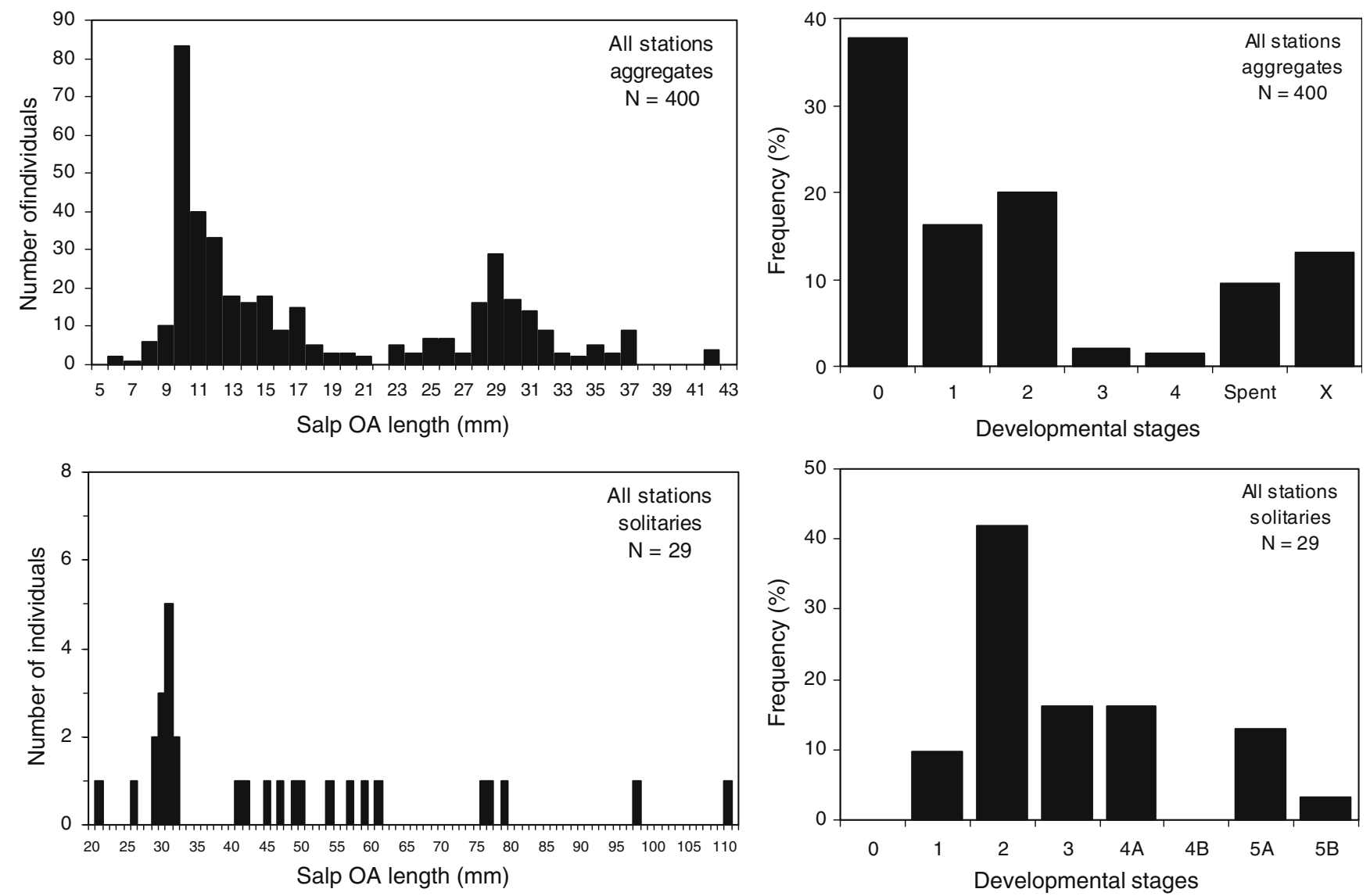

Fig. 4 Length frequency distribution and developmental composition of aggregate and solitary forms of Salpa thompsoni in the Eastern Bellingshausen Sea during austral autumn 2001

$4.848 \mu \mathrm{g}$ (pig) day ${ }^{-1}$, from 164 to $239 \mu \mathrm{g} \mathrm{C} \mathrm{day}{ }^{-1}$ and from 24 to $43 \mu \mathrm{g} \mathrm{N} \mathrm{day}^{-1}$, respectively (Table 3). Egestion accounted for $10-27 \%$ and $24-36 \%$ of ingestion in 13 and $30 \mathrm{~mm}$ aggregates, respectively, and as a consequence assimilation efficiency ranged from 73 to $90 \%$ and from 65 to $76 \%$ (Table 3 ).
The pellet pigment content increased dramatically with the salp length, averaging 320 and $2,526 \mathrm{ng}$ (pig) pellet ${ }^{-1}$ in 13 and $30 \mathrm{~mm}$ long aggregates. Two types of faecal pellets (namely compact and loose) were produced by both the $13 \mathrm{~mm}$ and $30 \mathrm{~mm}$ aggregates. Loose pellets were generally egested during the daytime

Table 2 Salpa thompsoni ingestion rates and daily rations estimated in the Eastern Bellingshausen Sea during April and May 2001

\begin{tabular}{|c|c|c|c|c|c|c|}
\hline \multirow[t]{2}{*}{ OAL (mm) } & \multirow[t]{2}{*}{$\mathrm{TL}(\mathrm{mm})$} & \multirow{2}{*}{$\begin{array}{l}\text { Carbon mass } \\
(\mathrm{mg})\end{array}$} & \multicolumn{2}{|c|}{ Daily ingestion rates } & \multirow{2}{*}{$\begin{array}{l}\text { Daily ration } \\
(\% \text { body } C)\end{array}$} & \multirow{2}{*}{$\begin{array}{l}\text { Daily FR } \\
\left(\text { ind }^{-1}\right)\end{array}$} \\
\hline & & & $\mu \mathrm{g}$ (pig) ind ${ }^{-1}$ & $\mathrm{mg} \mathrm{C}$ ind $^{-1}$ & & \\
\hline \multicolumn{7}{|c|}{ Aggregate forms } \\
\hline 10 & 14.5 & 0.338 & $2.792(1.497)$ & $0.254(0.090)$ & 74.9 & $3.1(5.4)$ \\
\hline 20 & 30.4 & 1.809 & $9.187(7.059)$ & $0.836(0.391)$ & 46.2 & $10.2(21.5)$ \\
\hline 30 & 46.2 & 4.819 & 13.93 (16.96) & $1.267(0.899)$ & 26.3 & $15.5(46.8)$ \\
\hline 40 & 62.1 & 9.657 & $26.16(31.52)$ & $2.380(1.622)$ & 24.6 & $29.1(81.1)$ \\
\hline \multicolumn{7}{|c|}{ Solitary forms } \\
\hline 20 & 21 & 2.501 & $0.146(3.252)$ & $0.013(0.187)$ & 0.5 & $0.2 ?(10.8)$ \\
\hline 40 & 42 & 7.793 & 3.751 (13.89) & $0.341(0.745)$ & 4.4 & $4.2(39.2)$ \\
\hline 60 & 63 & 15.151 & 24.99 (32.48) & $2.275(1.669)$ & 15.0 & $27.8(83.3)$ \\
\hline 80 & 83.5 & 24.284 & $96.03(58.61)$ & $8.739(2.925)$ & 36.0 & 106.7 (142) \\
\hline
\end{tabular}

Filtration rates (FR) were calculated assuming an average Chl- $a$ concentration of $0.9 \pm 0.6 \mu \mathrm{g} 1^{-1}$ (range $0.2-2.1 \mu \mathrm{g} \mathrm{l^{-1 }}$ ) at stations where salps were encountered. In brackets are parameters estimated using generalized rate models for $S$. thompsoni from Pakhomov et al. (2002): $\log \left(\mathrm{IR}\right.$ in $\mu \mathrm{g}(\mathrm{pig})$ ind $\left.^{-1} \mathrm{day}^{-1}\right)=2.0948 \log (\mathrm{TL}(\mathrm{mm}))+0.7424 ; \log \left(\mathrm{IR}\right.$ in $\mu \mathrm{g} \mathrm{C}$ ind $^{-1}$ day $\left.^{-1}\right)=1.9913 \log (\mathrm{TL}(\mathrm{mm}))-0.3605 ; \log$ $\left(\mathrm{FR}\right.$ in 1 ind $^{-1}$ day $\left.^{-1}\right)=1.8603 \log (\mathrm{TL}(\mathrm{mm}))-1.4266$

$O A L$ Oral-atrial length, $T L$ total length, $I R$ ingestion rate, $F R$ filtration rate 


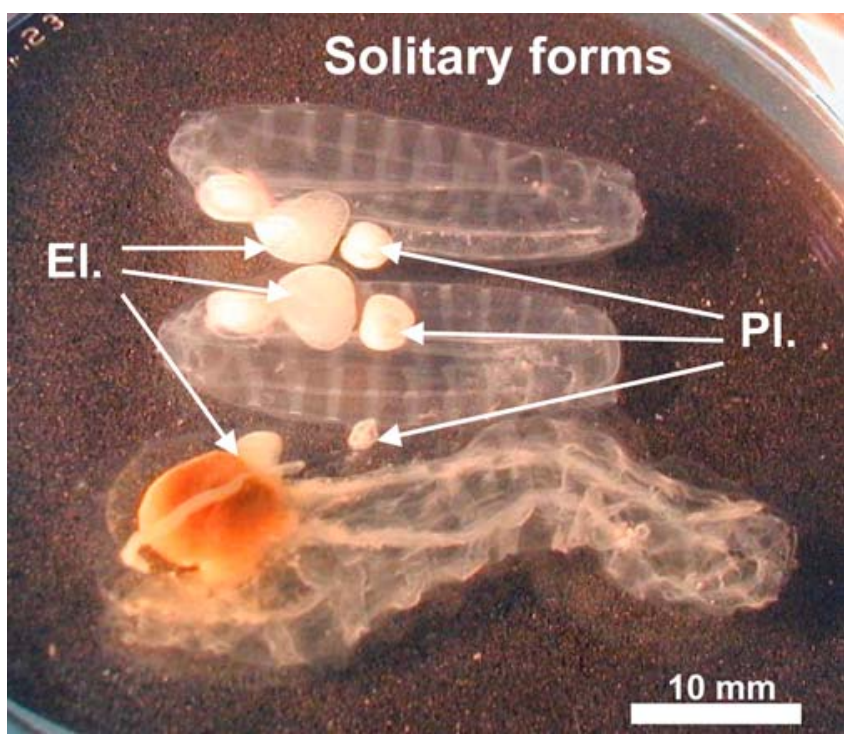

Fig. 5 Solitary forms of Salpa thompsoni with still present eleoblast $(E L)$ and placenta $(P L)$. Two top specimens retain embryo characteristics

and their pigment, carbon and nitrogen contents were significantly lower (ANOVA, $P<0.05$ ) than those of compact pellets (Fig. 9). Compact pellets of the $13 \mathrm{~mm}$ aggregates sank on average $1,640 \mathrm{~m} \mathrm{day}^{-1}$ or $1.9 \mathrm{~cm} \mathrm{~s}^{-1}$, while loose pellet sinking rate was significantly lower (ANOVA, $P<0.05$ ), averaging $760 \mathrm{~m} \mathrm{day}^{-1}$ or
$0.9 \mathrm{~cm} \mathrm{~s}^{-1}$ (Fig. 9). Average C:pigment ratio of faecal pellets were $273 \pm 177$ and $49 \pm 10$ in 13 and $30 \mathrm{~mm}$ aggregates, respectively. While there were no differences in C:pigment ratios between loose and compact pellets of the $30 \mathrm{~mm}$ aggregate ( $53 \pm 12$ vs. $45 \pm 9$ ), significant differences (ANOVA, $P<0.05$ ) in C:pigment ratio between loose and compact pellets of the $13 \mathrm{~mm}$ aggregate were found ( $446 \pm 72$ vs. $158 \pm 102$ ).

Daily salp ingestion was low, ranging from $<0.1$ to $0.9 \mathrm{mg}$ (pig) $\mathrm{m}^{-2}$, which accounted for $\leq 2 \%$ of Chl- $a$ standing stock (Table 1). Salp egestion rates varied between $<0.1$ and $0.3 \mathrm{mg}$ (pig) $\mathrm{m}^{-2}$ or $<1 \%$ of Chl- $a$ standing stock. Potential carbon flux via salp faecal pellets ranged from $<0.1$ to $16.2 \mathrm{mg} \mathrm{C} \mathrm{m}^{-2} \mathrm{day}^{-1}$ and was the highest at Bongo net stations (Table 1).

\section{Discussion}

Salp distribution and stage composition

Among regions of the Southern Ocean, the Bellingshausen Sea is regarded as the area where the cold form of $S$. thompsoni, previously described as Salpa gerlachei, is expected to predominate (Foxton 1966; Casareto and Nemoto 1987). However, in our collection there were no specimens displaying morphological characteristics of $S$. gerlachei. All analysed specimens had the characteristics of a typical Antarctic low-latitude S. thompsoni
Table 3 Pigment, carbon and nitrogen budgets for aggregates of Salpa thompsoni in the Eastern Bellingshausen Sea (30 mm OA length) and near Jubany Base $(13 \mathrm{~mm})$ during April and May 2001

\begin{tabular}{|c|c|c|c|}
\hline & Ingestion & Egestion & Assimilation \\
\hline \multicolumn{4}{|c|}{$\begin{array}{l}30 \mathrm{~mm} \text { Aggregate: } 3.685 \pm 0.238 \mathrm{mg} \mathrm{C} \text { ind }^{-1}, 0.828 \pm 0.057 \mathrm{mg} \mathrm{N} \text { ind }^{-1}, \mathrm{C} / \mathrm{N}=4.45 ; \text { Sta. } 328 \text { (night- } \\
\text { time): C:pigment ratio at } 10 \mathrm{~m} \text { depth } 64.5, \mathrm{C} / \mathrm{N}=5.1 \text {; Faecal pellets: average C:pigment ratio }=49.2 \text {, } \\
\mathrm{C} / \mathrm{N}=5.56\end{array}$} \\
\hline$\mu \mathrm{g}\left(\right.$ pig) ind $^{-1} \mathrm{day}^{-1}$ & 13.928 & 4.848 & 9.080 \\
\hline$\%$ of pigm ingested & 100 & 34.8 & 65.2 \\
\hline \multicolumn{4}{|l|}{ Carbon } \\
\hline mg C ind ${ }^{-1}$ day $^{-1}$ & 0.898 & 0.239 & 0.659 \\
\hline$\%$ of $\mathrm{C}$ ingested & 100 & 26.6 & 73.4 \\
\hline$\%$ of body $\mathrm{C}$ & 24.4 & 6.5 & 17.9 \\
\hline \multicolumn{4}{|l|}{ Nitrogen } \\
\hline $\mathrm{mg} \mathrm{N}$ ind ${ }^{-1} \mathrm{day}^{-1}$ & 0.176 & 0.043 & 0.133 \\
\hline$\%$ of $\mathrm{N}$ ingested & 100 & 24.4 & 75.6 \\
\hline$\%$ of body $\mathrm{N}$ & 21.3 & 5.2 & 16.1 \\
\hline \multicolumn{4}{|c|}{$13 \mathrm{~mm}$ Aggregate: $0.822 \pm 0.013 \mathrm{mg} \mathrm{C}$ ind $^{-1}, 0.151 \pm 0.043 \mathrm{mg} \mathrm{N}$ ind $^{-1}, \mathrm{C} / \mathrm{N}=5.44$; near Jubany } \\
\hline \multicolumn{4}{|c|}{$\begin{array}{l}\text { Base (daytime): C:pigment ratio at surface } 105, \mathrm{C} / \mathrm{N}=7.3 \text {; Faecal pellets: average C:pigment } \\
\text { ratio }=273, \mathrm{C} / \mathrm{N}=6.73\end{array}$} \\
\hline \multicolumn{4}{|l|}{ Pigments } \\
\hline$\mu g$ (pig) ind ${ }^{-1}$ day $^{-1}$ & 6.150 & 0.600 & 5.550 \\
\hline$\%$ of pigm ingested & 100 & 9.8 & 90.2 \\
\hline \multicolumn{4}{|l|}{ Carbon } \\
\hline mg C ind ${ }^{-1}$ day $^{-1}$ & 0.646 & 0.164 & 0.482 \\
\hline$\%$ of $\mathrm{C}$ ingested & 100 & 25.4 & 74.6 \\
\hline$\%$ of body $\mathrm{C}$ & 78.6 & 20.0 & 56.8 \\
\hline \multicolumn{4}{|l|}{ Nitrogen } \\
\hline $\begin{array}{l}\mathrm{mg} \mathrm{N} \text { ind day } \\
\% \text { of } \mathrm{N} \text { ingested }\end{array}$ & $\begin{array}{l}0.088 \\
100\end{array}$ & $\begin{array}{l}0.024 \\
27.3\end{array}$ & $\begin{array}{l}0.064 \\
72.7\end{array}$ \\
\hline$\%$ of body $\mathrm{N}$ & 58.3 & 15.9 & 42.4 \\
\hline
\end{tabular}



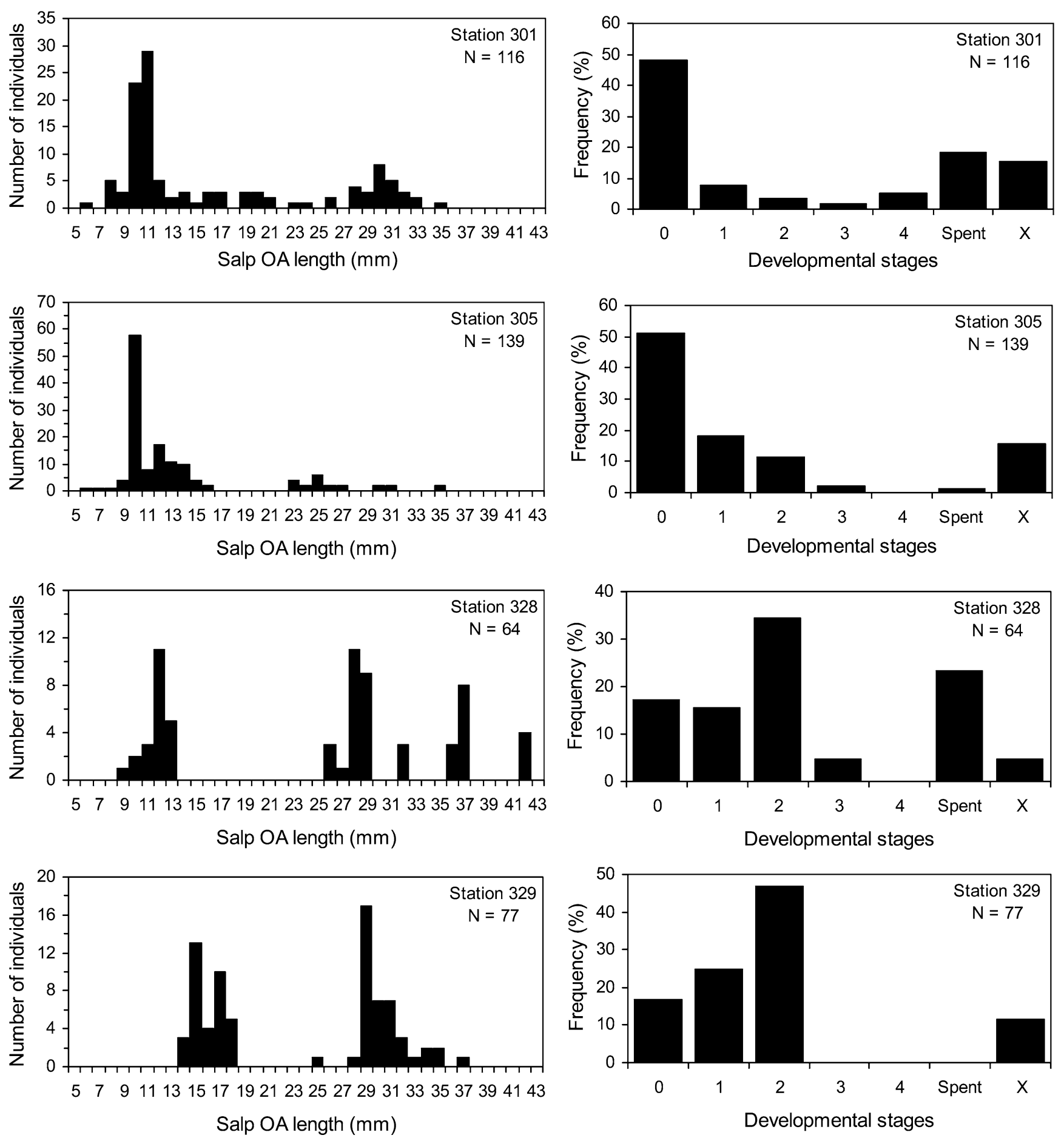

Fig. 6 Length frequency distribution and developmental composition of Salpa thompsoni aggregates at stations in the Eastern Bellingshausen Sea during austral autumn 2001

form (Foxton 1966). Despite being low-latitude animals, $S$. thompsoni have lately been observed repeatedly in the seas surrounding the Antarctic continent (Pakhomov et al. 2002). The frequency of occurrence of S. thompsoni in the Eastern Bellingshausen Sea (17-33\%) was within the lower range previously observed elsewhere around the Antarctic continent. For example, S. thompsoni occurrence at high latitudes varied generally between 20 and $68 \%$ in the RMT- 8 hauls (Boysen-Ennen and Piatkowski 1988; Piatkowski 1989; Siegel and Harm 1996; Hosie et al. 2000; Nicol et al. 2000). In the Lazarev Sea and off the Adelie Land (Eastern Antarctica), however, $S$. thompsoni were observed at $>80 \%$ of all stations (Pakhomov et al. 1994; Perissinotto and 
Fig. 7 Gut pigment content of Salpa thompsoni aggregate and solitary forms as a function of body length during austral autumn 2001 in the Eastern Bellingshausen Sea

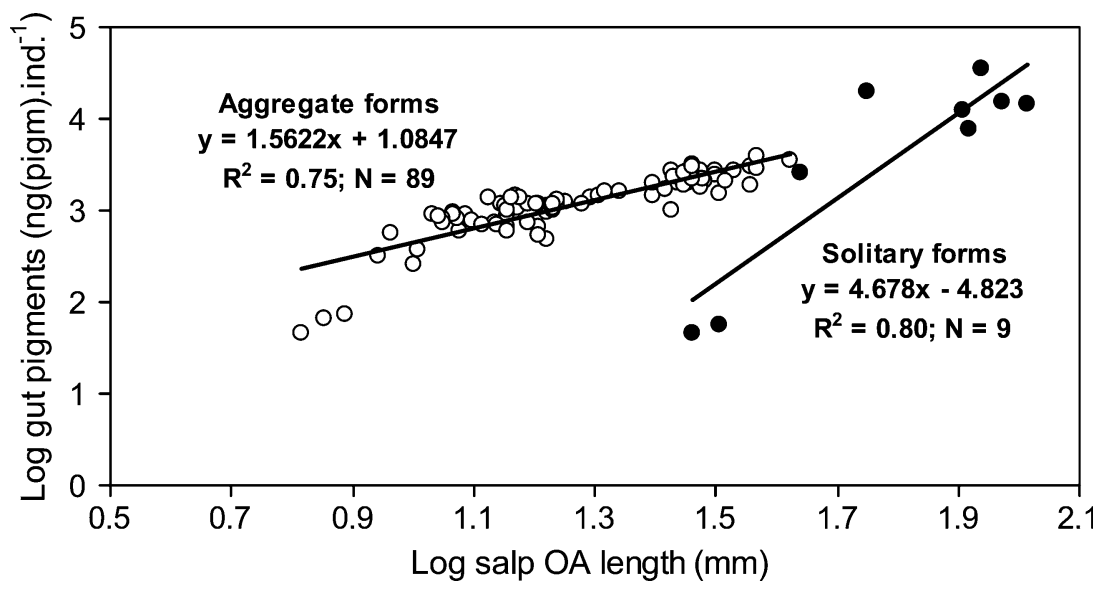

Pakhomov 1998a, b; Chiba et al. 1999). On both occasions, the salp distribution was positively correlated with water temperatures or deep warm water intrusions. A positive correlation was also observed between depthintegrated seawater temperature and $S$. thompsoni concentrations in the Cosmonaut Sea (Pakhomov 1991) and in the Prydz Bay region (Hosie et al. 1997). Although during our study no correlation between salp densities and seawater temperatures has been found, S. thompsoni were largely collected at stations influenced by the UCDW intrusions (Fig. 2, Table 1).

It has been postulated that salps, once advected into the Antarctic continental seas, may be trapped there under unfavourable environmental conditions (Pakhomov 1991; Siegel and Harm 1996; Chiba et al. 1999, Nicol et al. 2000). This was corroborated by the findings that advected salp populations were often composed of small-sized X-stage aggregates (Siegel and Harm 1996; Chiba et al. 1999, 2001). It has been hypothesized that low food availability and nearly freezing water temperatures may affect embryo development and adult growth of S. thompsoni (Chiba et al. 1999). Indeed, the contribution of the stage $\mathrm{X}$ among smaller aggregates in the Bellingshausen Sea was the highest, suggesting that earlier stages

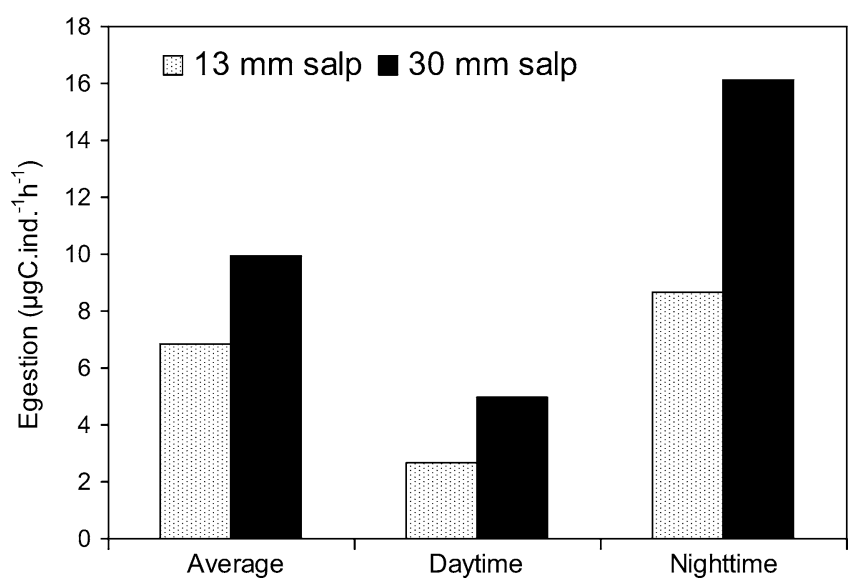

Fig. 8 Salpa thompsoni egestion rates of aggregate forms during austral autumn 2001 in the Eastern Bellingshausen Sea $(30 \mathrm{~mm}$ salp) and near South Shetland Islands (13 mm salp) may be more sensitive to unfavourable environmental conditions (Chiba et al. 1999). We cannot, however, discount the possibility that low water temperatures could have also affected salp fertilization rates. Solitary forms are generally absent in the coastal Antarctic seas (Pakhomov et al. 2002). Therefore, the presence of solitary forms retaining embryonic features ('retarded oozoids') may support an advection event. The spatial extent in occurrence of 'retarded oozoids' is currently unknown. Nevertheless, our limited data may suggest that if advected aggregate and solitary forms may react differently to water temperatures $<1^{\circ} \mathrm{C}$. Since Chl- $a$ concentrations were still sufficient in the region, water temperature would remain major factor affecting growth, development and, perhaps, fertilization rates within the S. thompsoni population. Low salp density might further jeopardize fertilization rates because another chain of aggregates at an advanced stage of development is required for the successful fertilization. Overall, it is not unreasonable to hypothesize that $S$. thompsoni population in the Eastern Bellingshausen Sea during fall 2001 may have been exposed to conditions close to its thermophysiological limits.

Oceanographic data indicated that during late fall of 2001 the Bellingshausen Sea shelf was greatly affected by the UCDW (see also Klinck et al. 2004). The wide extent of warm water intrusions was also confirmed by the presence in the region of investigation of some true Antarctic Circumpolar Current taxa, e.g. the lantern fish Electrona antarctica and the euphausiid Euphausia triacantha (RMT-8 hauls; E.A. Pakhomov, personal observation). Finally, postlarval Antarctic krill, which usually avoids such intrusions, was virtually absent in the area (Bathmann 2002). During depth stratified surveys, $S$. thompsoni was found to avoid cold-water layers, concentrating in either deep warm waters and/or in surface layers warmed during summer capping thus diminishing negative effects of cold waters (Pakhomov 1991; Pakhomov et al. 2002). During April and May 2001, surface RMT-8 hauls even during darkness yielded only a few $S$. thompsoni. This suggested that a limited number of salps preferred to travel near the surface and the majority would likely have concentrated below 
Fig. 9 Pigment content and sinking rates of compact and loose faecal pellets of Salpa thompsoni aggregates during austral autumn 2001 in the Eastern Bellingshausen Sea

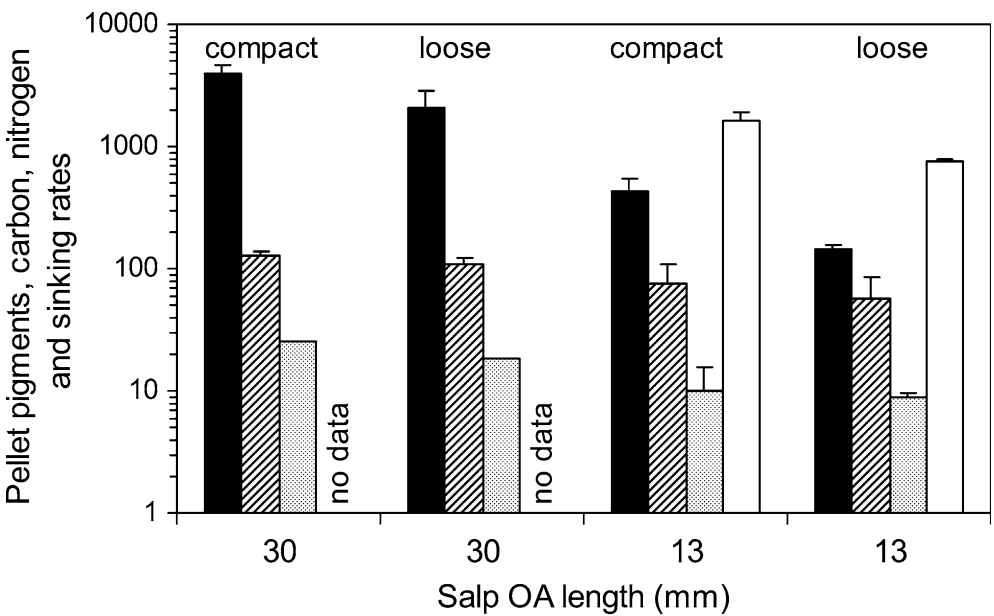

- Pellet pigments (ng pigm per pellet) $\square$ Pellet carbon ( $\mu \mathrm{g} \mathrm{C}$ ) 만 Pellet nitrogen $(\mu \mathrm{gN})$
50-100 m layer, e.g. in water layer with temperatures $>0.5^{\circ} \mathrm{C}$. Hence, the negative impact of cold-water temperatures may have been greatly reduced due to salp behaviour, e.g. their ability to concentrate in warmer water layers (Pakhomov et al. 2002).

The bimodal salp length frequency distribution in the Eastern Bellingshausen Sea during late fall was slightly unusual, suggesting that $S$. thompsoni from open waters to the north were only relatively recently advected into the region. Repeated oceanographic surveys in the Bellingshausen Sea during fall and winter 2001 showed that UCDW are pumped onto the continental shelf below $200 \mathrm{~m}$ four to six times in a year and may occur at scale of $\sim 45$ days (Klinck et al. 2004). Therefore, it could be speculated that intensive UCDV water intrusions not only brought salps into the region but also may have created conditions allowing the population to continue to grow and develop even at inner shelf stations.

Average densities of $S$. thompsoni were low but within the range recorded in the southern parts of the Southern Ocean (Pakhomov et al. 2002). However, maximum densities obtained with Bongo nets were comparable to these recorded around the Elephant Island and near the Antarctic Peninsula (e.g. Huntley et al. 1989; Nishikawa et al. 1995; Pakhomov et al. 2002). In summary, the S. thompsoni population in late fall 2001 in the Eastern Bellingshausen Sea, despite presence of 'retarded solitaries', showed many characteristics of their low latitude counterparts, which likely resulted from an intrusion and persistence of warmer deep waters over the shelf region.

\section{Feeding dynamics}

Estimating ingestion rates and daily rations from gut pigment contents has an advantage, as these values are the closest to in situ values (Madin and Kremer 1995). There are, however, some potential sources of error associated with the pigment based feeding rates. In this study, we did not have data on diel dynamics of gut pigments. Our gut evacuation and pigment destruction rates were taken from published sources, which may lead to an overestimate. Despite this, the pigment ingestion rates for aggregate forms in this study were in good agreement with rates obtained using a general model of the S. thompsoni ingestion (Pakhomov et al. 2002). Nevertheless, discrepancies in ingestion rate estimates by the two approaches were substantial for solitary forms $<50 \mathrm{~mm}$ long (Table 2). This may partially be explained by the fact that the generalized model was based mainly on measurements for aggregates with only limited data points for large $(>60 \mathrm{~mm})$ solitaries (Pakhomov et al. 2002). Furthermore, low ingestion rates of small oozoids during April/May 2001 were due to low gut pigment contents recorded in 'retarded solitaries'. Finally, in this study gut pigment data of solitary forms were limited to only nine measurements (Fig. 7). Therefore, solitary ingestion rates obtained here should be treated as preliminary rates (Table 2).

Daily ingestion rates in terms of carbon in the Eastern Bellingshausen Sea during late fall were within the range $\left(0.1-1.7 \mathrm{mg} \mathrm{C}\right.$ ind $\left.^{-1} \mathrm{day}^{-1}\right)$ previously reported for $S$. thompsoni in the Bransfield Strait and in the Lazarev Sea (Huntley et al. 1989; Perissinotto and Pakhomov 1998b). Daily rations in this study ranged from 15 to $75 \%$ of body carbon, which was again in line with literature values for $S$. thompsoni, 5-45\% of body carbon (Drits and Semenova 1989; Huntley et al. 1989; Pakhomov et al. 2002). Reported daily rations of temperate species appeared to be slightly higher varying between 59 and $117 \%$ of body carbon for three salp species, while for similarly sized salps daily rations are comparable (Deibel 1982; Andersen 1986; Madin and Purcell 1992). Substantial discrepancies between filtration rates of $S$. thompsoni determined during fall 2001 and calculated using the model in Pakhomov et al. (2002) were however observed. Salps are indiscriminate filter feeders, which are unable to regulate their filtration 
rates. As a consequence, ingestion rates would be largely a function of food availability and in turn filtration rates might be underestimated at high particle concentrations. Overall, however, it appears that $S$. thompsoni population in the Eastern Bellingshausen Sea during late fall 2001 was feeding at rates similar to those estimated in other regions of the Southern Ocean.

The carbon egestion rates estimated in this study were similar to those reported by Huntley et al. (1989) and Pakhomov et al. (2002). Interestingly, there were disparate trends in the pigment destruction in faeces estimated in the 30 and $13 \mathrm{~mm}$ aggregates. The $\mathrm{C}$ :pigment ratio in faeces of the $30 \mathrm{~mm}$ aggregate slightly decreased in comparison with $\mathrm{C}$ :pigment ratio of particulate matter, while it increased more than two-fold in faecal pellets of the $13 \mathrm{~mm}$ aggregate (Table 3 ). It should be noticed that the $30 \mathrm{~mm}$ aggregates were collected during darkness, while the $13 \mathrm{~mm}$ salps were collected during the day. There are two possible explanations for this observation. First, this may suggest more efficient pigment destruction to non-fluorescent products during the daytime. Findings of a previous study conducted north of the Lazarev Sea and results of the present study showed that egestion rates are lowest during the daytime, when salps migrate to deeper layers (Nishikawa and Tsuda 2001; Pakhomov 2004). Hence, a pronounced diel pattern in the salp digestion efficiency may occur because if food is retained longer in the salp guts, it is digested more efficiently. Indeed, $42-57 \%$ of ingested body nitrogen and carbon were assimilated during the day, while it does not exceed $18 \%$ during the hours of darkness (Table 3). Second, if we assume that salps continue feeding in the deeper water layers during the day, a deeper water $\mathrm{C}$ :pigment ratio should be used to convert salp gut pigments into carbon at station 330 conducted near Jubany Base. Unfortunately, at this station only surface $C$ :pigment ratios were available. However, in the Eastern Bellingshausen Sea, $\mathrm{C}$ :pigment ratio values deeper than $100 \mathrm{~m}$ often exceed 150 (M. Brichta and A. Belem, unpublished). Therefore, if C:pigment ratios of $\sim 150$ are used, ca. $28-38 \%$ of ingested nitrogen and carbon could be assimilated. Overall, however, the above implies that $S$. thompsoni may work as a more efficient re-packager of particles during darkness, while exposed to high food concentrations near surface layers. At the same time, salps behave mainly as digesters during the day in deeper layers. Although this is consistent with diel differences in egestion rates, it should be further investigated and used to improve modelling in salp faecal pellet production estimates.

Based on a pigment budget, assimilation efficiency of $S$. thompsoni in the region north of the Lazarev Sea was $44-78 \%$ with mean of $64 \%$ (Pakhomov 2004). Similarly, using carbon and nitrogen budgets, Huntley et al. (1989) showed that assimilation efficiency ranged from 51 to $59 \%$. Values obtained in this study $(65-90 \%)$ are within the higher range of previous estimates for S. thompsoni, while they are within the range of values reported for temperate salp species $(28-81 \%)$ and other herbivorous zooplankton ( 30 to $>90 \%$ ) (Omori and Ikeda 1984;
Andersen 1986; Madin and Purcell 1992; Madin and Deibel 1998).

Grazing impact of the $S$. thompsoni population in the Eastern Bellingshausen Sea was among the lowest previous estimates from different regions of the Southern Ocean, where salps are present (Dubischar and Bathmann 1997; Pakhomov et al. 2002). It was mainly due to low salp densities. However, at selected Bongo net stations it could reach levels similar to these during salp years in the Bransfield Strait and near Elephant Island (Huntley et al. 1989). Nevertheless, egestion accounted for a minor proportion of the Chl- $a$ standing stock in the area. The potential carbon flux via faeces during April/ May 2001 ranged from $<0.1$ to $16.2 \mathrm{mg} \mathrm{C} \mathrm{m}^{-2}$ day $^{-1}$. This was within the lower range $(0.1-$ $88 \mathrm{mg} \mathrm{C} \mathrm{m}^{-2}$ day $^{-1}$ ) estimated in the Bransfield Strait and in the Lazarev Sea (Huntley et al. 1989; Perissinotto and Pakhomov 1998a; Ross et al. 1998; Pakhomov 2004). Further, this would only account for a small to modest portion of the carbon flux (50 1,300 $\mathrm{mg} \mathrm{C} \mathrm{m}^{-2} \mathrm{day}^{-1}$ ) calculated using sediment trap collections (e.g. Schnack 1985; von Bodungen 1986; Bathmann et al. 1991). It may be concluded that salps advected into the shelf regions of coastal seas are unlikely major contributors to the grazing impact on the Chl- $a$ standing stock in these areas. The situation may however change if favourable environmental conditions, e.g. more often and extensive warm water intrusions (Klinck et al. 2004) or large-scale warming events (Levitus et al. 2000; Smedsrud 2005), allowing successful budding, growth and development of $S$. thompsoni persist for prolonged periods in coastal regions.

Acknowledgements We are grateful to the University of Fort Hare (South Africa), the Alfred Wegener Institute for Polar and Marine Research (Germany), the Alexander von Humboldt Foundation (Germany) and the University of British Columbia (Canada) for providing funds and facilities, which allowed conducting and completing this study. The professional and friendly support at sea by colleagues, the Captain and the crew of the RV Polarstern during the ANTATKTIS XVIII/5b cruise is greatly appreciated. B. Cisewski, H. Borth, B. Rabe, K. Rinas and C. Radke contributed to collecting the CTD data.

\section{References}

Andersen V (1986) Effect of temperature on the filtration rate and percentage of assimilation of Salpa fusiformis Cuvier (Tunicata: Thaliacea). Hydrobiologia 137:135-140

Atkinson A, Siegel V, Pakhomov EA, Rothery P (2004) Long-term decline in krill stock and increase in salps within the Southern Ocean. Nature 432:100-103

Baars MA, Helling GR (1985) Methodological problems in the measurements of phytoplankton ingestion rate by gut fluorescence. Hydrobiol Bull 19:81-88

Bathmann U (ed) (2002) The expedition ANTARKTIS XVIII/5b of the research vessel "Polarstern" in 2001. Berichte Polar Meeresforsch 407:1-98

Bathmann U, Fischer G, Müller PJ, Gerdes D (1991) Short-term variations in particular matter sedimentation off Kapp Norvegia, Weddell Sea, Antarctica: relation to water mass advection, ice cover, plankton biomass and feeding activity. Polar Biol 11:185-195 
Brichta M, Belem A (2002) Chlorophyll- $a$, particulate organic carbon/nitrogen $(\mathrm{POC} / \mathrm{N})$ and biogenic silica (Bsi) distribution. Berichte Polar Meeresforsch 407:61-64

von Bodungen B (1986) Phytoplankton growth and krill grazing during spring in the Bransfield Strait, Antarctica-implications from sediment trap collections. Polar Biol 6:153-160

Boysen-Ennen E, Piatkowski U (1988) Meso- and macrozooplankton communities in the Weddell Sea, Antarctica. Polar Biol 9:17-35

Casareto BE, Nemoto T (1986) Salps of the Southern ocean (Australian sector) during the 1983-84 summer, with special reference to the species Salpa thompsoni. Mem Natl Inst Polar Res 40:221-239

Casareto BE, Nemoto T (1987) Latitudinal variation of the number of muscle fibres in Sapla thompsoni (Tunicata, Thaliacea) in the Southern Ocean: implications for the validity of the species Salpa gerlachei. Proc NIPR Symp Polar Biol 1:90-104

Chiba S, Ishimaru T, Hosie GW, Wright SW (1999) Population structure change of Salpa thompsoni from austral mid-summer to autumn. Polar Biol 22:341-349

Chiba S, Ishimaru T, Hosie GW, Fukuchi M (2001) Spatio-temporal variability of zooplankton community structure off east Antarctica $\left(90\right.$ to $\left.160^{\circ} \mathrm{E}\right)$. Mar Ecol Prog Ser 216:95-108

Cisewski B, Strass V, van Franeker JA (2002) Underway measurements of currents with the vessel-mounted acoustic doppler current profiler. Berichte Polar Meeresforsch 407:16-18

Conover RJ, Durvasula R, Roy S, Wang R (1986) Probable loss of chlorophyll-derived pigments during passage through the gut of zooplankton and some of the consequences. Limnol Oceanogr 31:878-887

Daponte MC, Capitanio FL, Esnal GB (2001) A mechanism for swarming in the tunicate Salpa thompsoni (Foxton, 1961). Ant Sci 13:240-245

Deibel D (1982) Laboratory determined mortality, fecundity and growth rates of Thalia democratica Forskal and Dolioletta gegenbauri Uljianin (Tunicata, Thaliacea). J Plank Res 4:143-153

De la Mare WL (1997) Abrupt mid-twentieth-century decline in Antarctic sea-ice extent from whaling records. Nature 389:57-60

Drits AV, Semenova TN (1989) Trophic characteristics of major planktonic phytphages from South Shetland Islands region during early spring. In: Ponomareva LA (ed) Complex investigations of the pelagic zone of the Southern Ocean (in Russian). Shirshov Institute Oceanology Publishers, Moscow, pp 66-78

Dubischar CD, Bathmann UV (1997) Grazing impact of copepods and salps on phytoplankton in the Atlantic sector of the Southern Ocean. Deep Sea Res II 44:415-433

Dubischar C, Pakhomov EA, Bathmann UV (2005) The tunicate Salpa thompsoni ecology in the Southern Ocean. II. Proximate and elemental composition. Mar Biol (submitted)

Foxton P (1966) The distribution and life history of Salpa thompsoni Foxton with observations on a related species S. gerlachei Foxton. Discov Rep 34:1-116

Harbison GR, McAlister VL, Gilmer RW (1986) The response of the salp, Pegea confoederata, to high levels of particulate material: Starvation in the midst of plenty. Limnol Oceanogr $31: 371-382$

Hosie GW, Cochran TG, Pauly T, Beaumont KL, Wright SW, Kitchener JA (1997) Zooplankton community structure of Prydz bay, Antarctica, January-February 1993. Proc NIPR Symp Polar Biol 10:90-133

Hosie GW, Schultz MB, Kitchener JA, Cochran TG, Richards K (2000) Macrozooplankton community structure off East Antarctica $\left(80-150^{\circ} \mathrm{E}\right)$ during the austral summer of $1995 / 1996$. Deep Sea Res II 47:2437-2463

Huntley ME, Sykes PF, Marin V (1989) Biometry and trophodynamics of Salpa thompsoni Foxton (Tunicata: Thaliacea) near the Antarctic Peninsula in Austral summer, 1983-1984. Polar Biol 10:59-70

Klinck JM, Hofmann EE, Beardsley RC, Salihoglu B, Howard S (2004) Water-mass properties and circulation on the west Antarctic Peninsula continental shelf in austral fall and winter 2001. Deep Sea Res II 51:1925-1946
Le Fèvre J, Legendre L, Rivkin RB, (1998) Fluxes of biogenic carbon in the Southern Ocean: roles of large microphagous zooplankton. J Mar Syst 17:325-345

Levitus A, Antonov JI, Boyer TP, Stephens C (2000) Warming of the World Ocean. Science 287:2225-2229

Loeb V, Siegel V, Holm-Hansen O, Hewitt R, Fraser W, Trivelpiece W, Trivelpiece S (1997) Effects of sea-ice extent and krill or salp dominance on the Antarctic food web. Nature 387:897-900

Mackas D, Bohrer R (1976) Fluorescence analysis of zooplankton gut contents and an investigation of diel feeding patterns. J Exp Mar Biol Ecol 25:77-85

Madin LP, Deibel D (1998) Feeding and energetics of Thaliacea. In: Bone Q (ed) The biology of pelagic tunicates. Oxford University Press, Oxford, pp 81-104

Madin LP, Kremer R (1995) Determination of the filter-feeding rates of salps (Tunicata, Thaliacea). ICES J Mar Sci 52:583-595

Madin LP, Purcell JE (1992) Feeding, metabolism, and growth of Cyclosalpa bakeri in the subarctic Pacific. Limnol Oceanogr 37:1236-1251

Moline MA, Claustre H, Frazer TK, Grzymski J, Schofield O, Vernet M (2000) Changes in phytoplankton assemblages along the Antarctic Peninsula and potential implications for the Antarctic food web. In: Davison W, Howard-Williams C, Broady P (eds) Antarctic ecosystems: models for wider ecological understanding. The Caxon Press, Christchurch, pp 263-271

Nicol A, Pauly T, Bindoff NL, Wright S, Thlele D, Hosie GW, Strutton PG, Woehler E (2000) Ocean circulation off east Antarctica affects ecosystem structure and sea-ice extent. Nature 406:504-507

Nishikawa J, Tsuda A (2001) Diel vertical migration of the tunicate Salpa thompsoni in the Southern Ocean during summer. Polar Biol 24:299-302

Nishikawa J, Naganobu M, Ichii T, Ishii H, Terazaki M, Kawaguchi K (1995) Distribution of salps near the South Shetland Islands during austral summer, 1990-1991 with special reference to krill distribution. Polar Biol 15:31-39

Omori M, Ikeda T (1984) Methods in marine zooplankton ecology. Wiley, New York, 323pp

Pakhomov EA (1991) Antarctic macroplankton and the nutrition of coastal fishes (in Russian). PhD Thesis, P.P. Shirshov Institute of Oceanology, Russian Academy of Sciences, Moscow, pp 1-263

Pakhomov EA (2004) Salp/krill interactions in the eastern Atlantic sector of the Southern Ocean. Deep Sea Res II 51:2645-2660

Pakhomov EA, Froneman PW (2004) Mesozooplankton dynamics in the eastern Atlantic sector of the Southern Ocean during the austral summer 1997/1998. 2. Grazing impact. Deep Sea Res II 51:2617-2631

Pakhomov EA, Grachev DG, Trotsenko BG, (1994) Distribution and composition of macroplankton communities in the Lazarev Sea (Antarctic). Oceanology 33:635-642

Pakhomov EA, Froneman PW, Perissinotto R (2002) Salp/krill interactions in the Southern Ocean: spatial segregation and implications for the carbon flux. Deep Sea Res II 49:1881-1907

Pakhomov EA, Fuentes V, Schloss I, Atencio A, Esnal GB (2003) Beaching of the tunicate Salpa thompsoni at high levels of suspended particulate matter in the Southern Ocean. Polar Biol 26:427-431

Perissinotto R, Pakhomov EA (1998a) Contribution of salps to carbon flux of marginal ice zone of the Lazarev Sea, southern ocean. Mar Biol 131:25-32

Perissinotto R, Pakhomov EA (1998b) The trophic role of the tunicate Salpa thompsoni in the Antarctic marine ecosystem. J Mar Syst 17:361-374

Piatkowski U (1989) Macrozooplankton communities from Weddell Sea surface waters, Antarctica. Pesq Antárt Bras 1:1-10

Ross RM, Quetin LB, Haberman KL (1998) Interannual and seasonal variability in short-term grazing impact of Euphausia superba in nearshore and offshore waters west of the Antarctic Peninsula. J Mar Syst 17:261-273 
Schnack SB (1985) A note on the sedimentation of particulate matter in Antarctic waters during summer. Meeresforschung 30:306-315

Siegel V, Harm U (1996) The composition, abundance, biomass and diversity of the epipelagic zooplankton communities of the southern Bellingshausen Sea (Antarctic) with special reference to krill and salps. Arch Fish Mar Res. 44:115-139

Smedsrud LH (2005) Warming of the deep water in the Weddell Sea along the Greenwich meridian: 1977-2001. Deep Sea Res I 52:241-258

Smith DA, Hofmann EE, Klinck JM, Lascara CM (1999) Hydrography and circulation of the West Antarctic Peninsula Continental Shelf. Deep Sea Res I 46:925-949
Strickland JDH, Parsons TR (1968) A practical handbook of seawater analysis. Bull Fish Res Bd Canada 167:1-311

Voronina NM (1998) Comparative abundance and distribution of major filter-feeders in the Antarctic pelagic zone. J Mar Syst 17:375-390

Walsh JJ, Dieterle DA, Lenes J (2001) A numerical analysis of carbon dynamics of the Southern Ocean phytoplankton community: the roles of light and grazing in effecting both sequestration of atmospheric $\mathrm{CO}_{2}$ and food availability to larval krill. Deep Sea Res I 48:1-48 